Original Research article

\title{
Effect of Ni and Pd Transition Metal Functionalized on Interaction of Mercaptopyridine with B12N12 Nanocage: NBO, AIM, DFT, TD-DFT Study
}

\section{Rezaei-Sameti*, M. Jafari}

Department of Applied Chemistry, Faculty of Science, Malayer University, Malayer, 65174-79117, Iran

\section{ARTICLE INFORMATION}

Received: 27 December 2019

Received in revised: 08 March 2020

Accepted: 04 April 2020

Available online: 01 July 2020

DOI: $10.33945 /$ SAMI/CHEMM.2020.4.10

\section{KEYWORDS}

\section{B12N12}

Mercaptopyridine

$\mathrm{Ni}$ and Pd functionalized

DFT

NBO

MEP

RDG

\begin{abstract}
In this work, the effect of the functionalized $\mathrm{Ni}$ and Pd transition metals on interaction of the mercaptopyridine (MCP) with the boron nitride nanocage (B12N12) was investigated using the density functional theory (DFT) and TDDFT method. The selected structures were optimized using the camB3LYP/Lanl2DZ level of theory. The adsorption energy and enthalpy values of MCP on the surface of pristine, Ni, and Pd functionalized B12N12 nanocage were negative and all adsorption process were exothermic. The results of the recovery time indicated that the pristine B12N12 nanocage with the lowest recovery time was suitable for making sensitive sensor for MCP molecule and the Ni functionalized B12N12 with the most recovery time that was favorable for making the adsorbent of the MCP molecule. The reduced gradient density (RDG) and quantum theory of atom in molecule (QTAIM) outputs revealed that the interaction of MCP with the Ni functionalized B12N12 were stronger than that of the pristine model. The UV-visible results confirmed that the adsorption of MCP on the surface of the Ni functionalized B12N12 with the most value of $\lambda_{\max }$ was suitable as absorbent in UV area.

Copyright (C) 2020 by SPC (Sami Publishing Company)

Chemical Methodologies: http://www.chemmethod.com/
\end{abstract}

\section{Graphical Abstract}
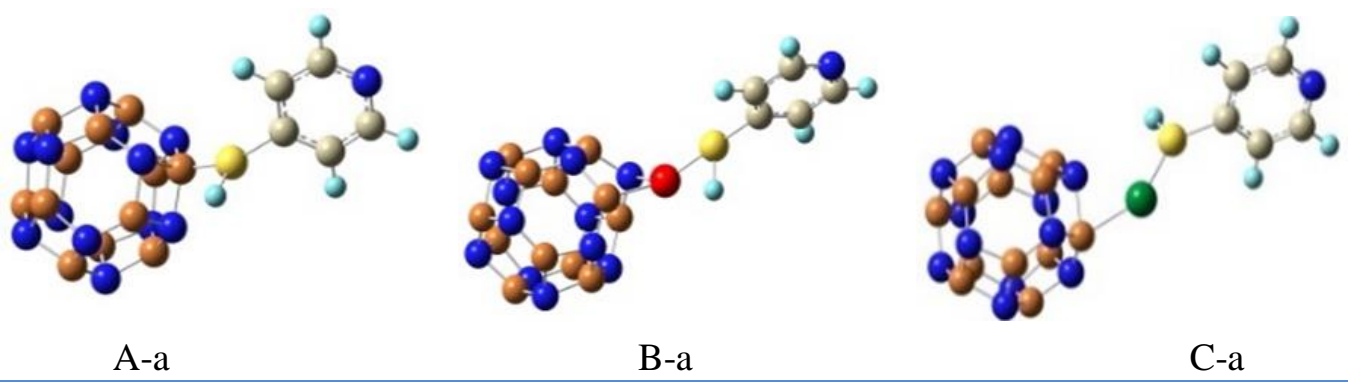

B-a

$\mathrm{C}-\mathrm{a}$

*Corresponding author: E-mail: (mrsameti@gmail.com) (mrsameti@malayeru.ac.ir), Department of Applied Chemistry, Faculty of Science, Malayer University, Malayer, 65174-79117, Iran, Tel: +988132355404 


\section{Introduction}

4-Mercaptopyridine (MCP) with the formula of $\mathrm{C}_{5} \mathrm{H}_{4} \mathrm{NSH}$ is a typical aromatic thiol compound. This compound has a thiol group in the position para to $\mathrm{N}$ atom in the pyridine ring. The MCP compounds and its derivatives have been mostly used as a protecting group for amines and imides, acylating agents, intermediate to self-assembly process and monolayers on surface of the silver and gold surfaces [1-4]. Taniguchi et al. [5] and Gui et al. [6] investigated the adsorption of MCP on the surface of Au (111) and Ag (111) electrodes, respectively, which caused modification of surface towards electrochemical detections and sensors. Shokuhi Rad [7] studied the adsorption of the MCP on the surface of Al- and B-doped graphene. The result of this study revealed that the adsorption on the surface of $B$-doped graphene was considerable at proper configuration; however, it was lower than that of the $\mathrm{Al}$-doped graphene.

In the recent years, many researches have focused on investigating the properties of the fullerene-like nanocage and nanoclusters due to their special physical, chemical, optical, and electrical properties [8-13]. In this regard, the boron nitride (BN) nanocage with different number of boron and nitrogen atoms have gained much interest due to its unique structural, electrical, microelectronic, optical properties, and magnetic properties such as Coulomb blockade, photoluminescence and super magnetism [14-19]. Seifert et al. [19] theoretically showed that the B12N12, B16N16, and B28N28 were magic stable BN fullerenes and B12N12 cage was more stable than one among them. B12N12 cage was synthesized by Oku et al. [18] and then detected by laser desorption time-off-light mass spectrometry. This study demonstrated that the synthesized clusters consist of six and eight 4- and 6membered BN rings that were more stable than other states. Beheshtian et al. [16] found that the B12N12 cage was thermodynamically more stable compared with the B12P12 at ambient condition. Bahrami and coworkers [20] showed that the B12N12 nanocage could be regarded as a potential sensor for adsorption of amphetamine in environmental systems. Other reports revealed that the B12N12 could effectively adsorb and decompose the methanol molecule at room temperature, due to the ionic nature of B-N bonds [21]. Shakerzadeh investigated the interaction between the formaldehyde monomer $\left(\mathrm{H}_{2} \mathrm{CO}\right)$ as well as dimer $\left(\left(\mathrm{H}_{2} \mathrm{CO}\right)_{2}\right)$ with pristine B12N12 nanocluster. The result of this study showed that in contrary to the pristine boron nitride nanotube and nanosheet, formaldehyde adsorption induced considerable change in the electronic properties of the B12N12 nanocluster [22]. The B12N12 nanocluster was a good adsorbent for several molecules such as halomethanes [23], ammonia [24], $\mathrm{CO}$ [25-26], $\mathrm{CO}_{2}$ [27], NO, $\mathrm{N}_{2} \mathrm{O}$ [28], $\mathrm{H}_{2}$ [29], $\mathrm{N}_{2}, \mathrm{CH}_{4}$ [30], pyrrole [31], phosgene [32], cysteine [33], methylamine [34], $\mathrm{X}_{2}$ molecules (X: Li, Be, B, N, O, F, Cl, Br, I) [35], O3, and $\mathrm{SO}_{2}$ [36]. 
Following our previous work [37-41], in this project, we decided to investigate the adsorption of mercaptopyridine (MCP) molecule on the surface of pristine and $\mathrm{Ni}, \mathrm{Pd}$ functionalized boron nitride nanocluster (B12N12). For this purpose, the geometrical and electrical properties of MCP/B12N12 complex were calculated at the cam-B3LYP level of theory. The quantum parameters, thermodynamic, solvent effect, reduced density gradient, atom in molecule parameters and UV-visible spectrums of all studied systems were determined. The calculated results may be useful for making adsorbent and detector for MCP molecule.

\section{Experimental}

\section{Computational details}

In this work, at the first step, we considered different configurations for adsorption MCP on the surface of (BN) 12 nanocage, and then all configurations were optimized with B3LYP/3-21G. The stable configurations were denoted with A-a, A-d for pristine state, B-a, B-d, C-a and C-d for Ni and Pd functionalized B12N12, respectively. The and $\mathbf{d}$ symbols were used to determine the adsorption orientations of the MCP from S and N (see Figure 1). All the calculations were performed using the Gaussian 09 electronic structure package [42]. The geometries of the A-a, A-d, B-a, B-d, C-a, and C-d models were fully optimized at the cam-B3LYP/Lanl2dz levels of theory to obtain the most stable complexes. The coulomb-attenuating method of B3LYP level of theory (CAM-B3LYP) provided accurate results in comparison with the other available functionals [43].
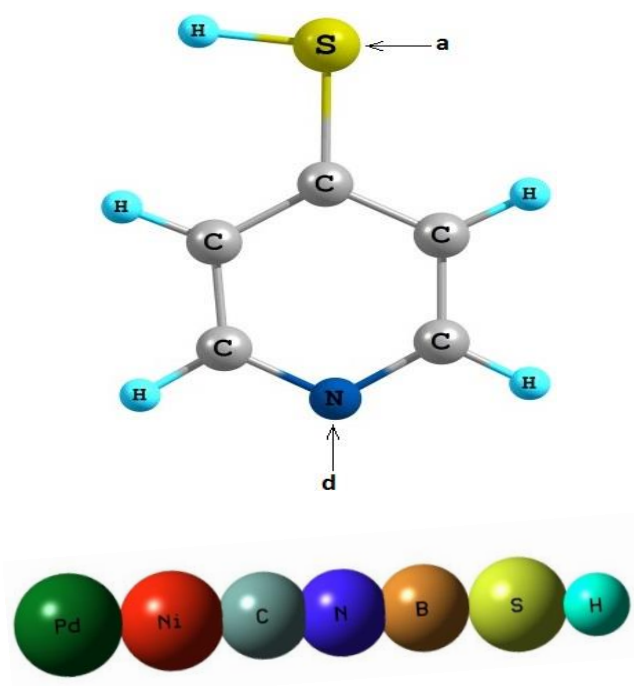

Figure 1. The adsorption positions of mercaptopyridine (MCP) molecule on the surface of the pristine and Ni, Pd functionalized B12N12 nano cage

The optimization criteria of system are Max force=0.00045; RMS force=0.0003; Max displacement $=0.0018$ and RMS displacement=0.0012. At all the optimized structures, there was no any 
imaginary frequency. The adsorption energy $\left(E_{\text {ads }}\right)$ and thermodynamic parameters for MCP adsorption on the surface of B12N12 for all the considered models were calculated using the Equation 1.

$$
\Delta Q=Q_{M P Y / B 12 N 12}-\left(Q_{M P Y}+M_{B 12 N 12}\right) \quad Q: E_{a d s}, H, G, S
$$

Where $\mathrm{Q}_{(\mathrm{MCP} / \mathrm{B} 12 \mathrm{~N} 12)}$ is the total energy of the MCP/B12N12 complex, $\mathrm{Q}_{(\mathrm{MCP})}$ and $\mathrm{Q}_{(\mathrm{B} 12 \mathrm{~N} 12)}$ are the total energy of MCP and pristine, Ni, Pd functionalized B12N12 nanocluster respectively. The solvent (water and ethanol) effects were determined by means of the polarizable continuum model (PCM) [44]. From the optimized structures, the quantum descriptive parameters such as HOMO (highest occupied molecular orbital), LUMO (lowest unoccupied molecular orbital), gap energy ( $E_{\text {gap }}$ ), electronic chemical potential $(\mu)$, global hardness $(\eta)$, electrophilicity $(\omega)$ and total charge transfer parameters $(\Delta N)$ [45-50] were calculated at the above level of theory, and the calculated results are tabulated in Table 1.

$$
\begin{aligned}
& E_{\text {gap }}=E_{\text {LUMO }}-E_{\text {HOMO }} \\
& \eta=\frac{E_{\text {LUMO }}-E_{\text {HOMO }}}{2} \\
& \mu=\frac{E_{\text {LUMO }}+E_{\text {HOMO }}}{2} \\
& \Delta N=\frac{\mu}{\eta} \\
& \omega=\frac{\mu^{2}}{2 \eta}
\end{aligned}
$$

Table 1. Thermodynamic, adsorption energy, deformation energy, solvent effect parameters of mercaptopyridine adsorption on the surface of pristine and Ni functionalized B12N12

\begin{tabular}{|c|c|c|c|c|c|c|}
\hline properties & A-a & A-d & B-a & B-d & C-a & C-d \\
\hline$\Delta \mathrm{H} / \mathrm{Kcal} / \mathrm{mol}$ & -17.28 & -44.15 & -25.33 & -46.91 & -21.01 & -35.16 \\
\hline$\Delta \mathrm{G} / \mathrm{Kcal} / \mathrm{mol}$ & -5.93 & -31.2 & -13.86 & -33.50 & -9.96 & -23.62 \\
\hline $\mathrm{E}_{\text {ads }} / \mathrm{Kcal} / \mathrm{mol}$ & -8.60 & -46.47 & -26.85 & -48.12 & -22.47 & -36.86 \\
\hline $\mathrm{E}_{\text {def(B12N12) }} / \mathrm{Kcal} / \mathrm{mol}$ & -7.05 & -18.43 & -0.68 & -0.84 & -0.22 & -0.75 \\
\hline $\mathrm{E}_{\text {def(MPY) }} / \mathrm{Kcal} / \mathrm{mol}$ & -0.58 & -0.95 & -0.56 & -0.37 & -1.16 & -0.31 \\
\hline$\Delta \mathrm{G}_{(\text {water })} / \mathrm{Kcal} / \mathrm{mol}$ & 4.95 & 5.97 & -25.04 & -21.05 & -17.57 & -14.04 \\
\hline$\Delta \mathrm{G}_{\text {(Ethanol } / \mathrm{Kcal} / \mathrm{mol}}$ & 4.91 & 6.01 & -27.74 & -22.84 & -17.03 & -13.77 \\
\hline $\mathrm{d}_{\mathrm{B} 12 \mathrm{~N} 12 / \mathrm{MPY} / \mathrm{A}}$ & 2.19 & 1.59 & 2.27 & 1.89 & 2.45 & 2.10 \\
\hline$\mu_{\mathrm{B} 12 \mathrm{~N} 12 / \mathrm{MPY}} / \mathrm{Debye}$ & 5.27 & 10.57 & 6.64 & 10.78 & 5.54 & 8.91 \\
\hline
\end{tabular}

These parameters reflect the reactivity, conductivity, and optical properties of the molecule. A molecule having small gap energy is more polarizable and is generally associated with a high chemical reactivity and low kinetic stability. The natural bond orbital (NBO) [51] analysis, reduced density gradient (RDG) [51-52] analysis are performed at the above level of theory. 


\section{Results and discussion}

\section{Geometrical and adsorption energy and thermodynamic parameters}

The optimized structures of pristine B12N12 nanocage reveal that the average B-N bond length in six tetragonal and eight hexagonal BN ring is 1.51 and $1.45 \AA$ A respectively, which is in good agreement with other related works [53-55] (see the Table S1 in supplementary data).

One of the effective methods to modify the chemical, physical, and electrical properties of system is functionalization transition metals on the surface of single wall of nanomaterial due to catalyst properties of this metal in the biological system. In this work, $\mathrm{Ni}$ and $\mathrm{Pd}$ atoms were functionalized over the BN bond of B12N12 nanocage and the geometrical structural of Ni, Pd functionalized B12N12 were optimized. The results indicated that, the B-N bond length altered slightly from the pristine model. For exploring the sensing properties of the pristine, Ni and Pd functionalized B12N12 nanocage for MCP molecule, we considered different adsorption configurations to find the most suitable models. After optimizing all the structures, we selected six stable configurations without imaginary frequency (Figure 2). The cohesion energy in the pristine and Ni, Pd functionalized B12N12 was $-3806.85,-3870.89$ and $-3838.01 \mathrm{Kcal} / \mathrm{mol}$, respectively. The results revealed that, the Ni and Pd functionalized B12N12 was more stable than the pristine model. The average B-N bond length in six tetragonal and eight hexagonal BN ring in the A-a and A-d models were (1.50 and 1.47 $\AA$ ) and (1.51 and 1.47 $\AA$ ), respectively. In the B-a, B-d models were (1.50 and 1.49 ̊) and (1.51 and 1.48 ̊̊), respectively, in the C-a, C-d models were (1.51 and $1.48 \AA$ ) and (1.52 and $1.47 \AA$ ), respectively (Figure S1-S2 in supplementary data).

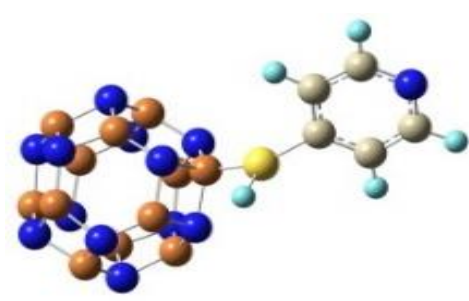

A-a

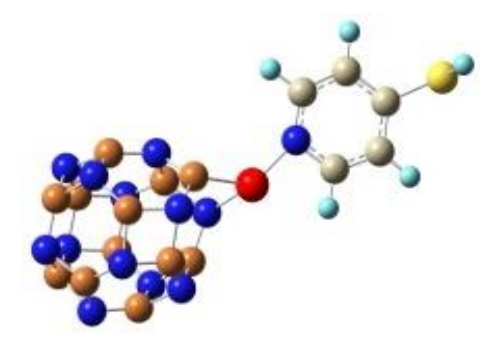

B-d

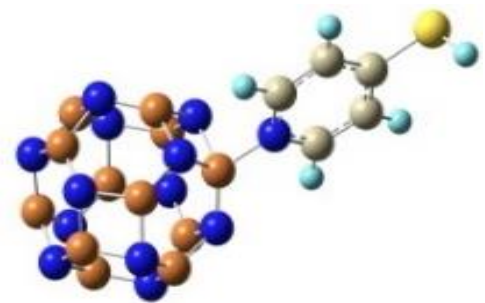

A-d

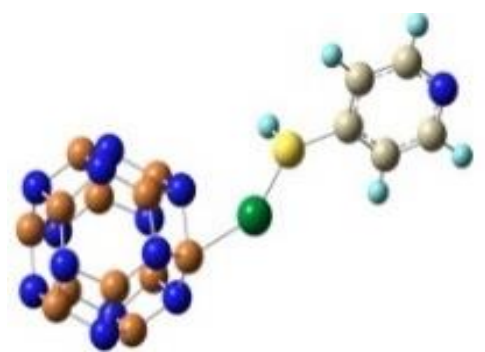

C-a

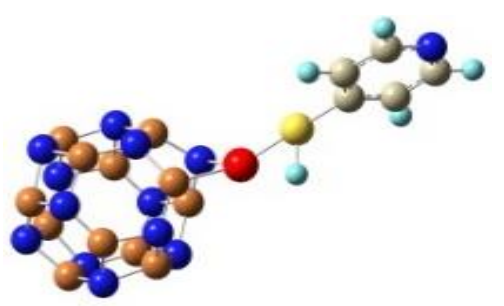

B-a

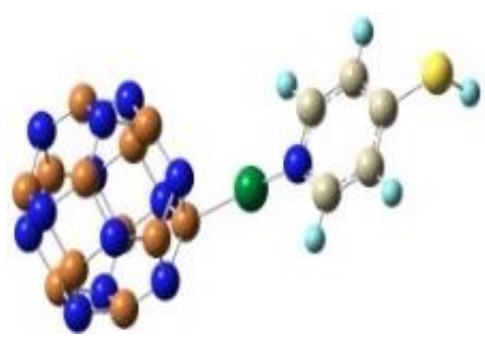

C-d

Figure 2. 2D views of MCP molecule on the surface of the pristine and Ni, Pd functionalized B12N12 nano cage at the A-a to C-d adsorption models 
From NBO results, it was found that, the NBO charge of the boron and nitrogen atoms in B12N12 was 1.211 and $-1.211|\mathrm{e}|$, respectively, and the hybridization of $\mathrm{B}$ atom in the $\mathrm{B}-\mathrm{N}$ bonds was $\mathrm{SP}^{2.27}$ and these results were in agreement with other reports [57]. With functionalizing Ni atom the NBO charges of boron, nitrogen and nickel atoms were $1.232,-1.247$ and $0.507|\mathrm{e}|$, respectively, the hybridization of $\mathrm{B}$ atom in the B-N bonds is SP2.25. In the Pd functionalized the NBO charge of boron, nitrogen and palladium atoms were $1.210,-1.230$ and $0.328|\mathrm{e}|$, respectively, the hybridization of B atom in the B-N bonds was SP2.28. The NBO outcomes for A-a, B-a and C-a models revealed that the NBO charge of boron and nitrogen atoms in MCP/B12N12 complex were 1.071 and -1.270 |e|, respectively. The NBO charges of boron, nitrogen, and nickel atoms in MCP/Ni \& B12N12 were 0.957, -1.247 and $0.253|\mathrm{e}|$, respectively, and the NBO charges of boron, nitrogen, and palladium atoms in MCP/Pd \& B12N12 were 1.000, -1.285 and $0.157|\mathrm{e}|$ respectively. By using Equation 1, the adsorption energy and thermodynamic parameters of MCP adsorption on B12N12, Ni, and Pd and B12N12 were calculated, and the results are listed in Table 1. Inspection of the obtained results indicated that the adsorption energy and enthalpy values of the A-a, A-d, B-a, B-d, C-a, and C-d models were negative and exothermic in view of thermodynamic point. Comparison results confirmed that the adsorption of MCP on surface of B12N12 from S site of adsorbent is in order: Ba $(-26.85 \mathrm{Kcal} / \mathrm{mol})>\mathrm{C}-\mathrm{a}(-22.47 \mathrm{Kcal} / \mathrm{mol})>\mathrm{A}-\mathrm{a}(-8.60 \mathrm{Kcal} / \mathrm{mol})$, wherein from $\mathrm{N}$ site of adsorbent is in order: B-d (-48.12 Kcal $/ \mathrm{mol})>\mathrm{C}-\mathrm{d}(-36.86 \mathrm{Kcal} / \mathrm{mol})>\mathrm{A}-\mathrm{d}(-8.09 \mathrm{Kcal} / \mathrm{mol})$. Interestingly, when the MCP from $\mathrm{N}$ head was approaching to the nano-cluster, the adsorption of MCP on the surface of B12N12 was more appropriate than the S site of MCP as the values of adsorption energy for the $\mathbf{d}$ orientation was more than the a orientation. Furthermore, the adsorption of MCP on the surface of Ni functionalized B12N12 was more stable than the pristine and Pd functionalized.

The bond distance between MCP and nanocluster and dipole moment of MCP/nano cage complex for A-d, B-d and C-d adsorption models were found to be (1.59 Å and 11.57 Debye), (1.89 Å and 10.87 Debye) and (2.10 A and 8.91 Debye) respectively. On the other hand, the bond distance between MCP and nano cage and dipole moment of MCP/nano cage complex for A-a, B-a and C-a adsorption models were $(2.19 \AA$ and 5.27 Debye), (2.27 $\AA$ and 6.64 Debye) and (2.45 $\AA$ and 5.54 Debye), respectively. Inspection of results indicated that when MCP adsorbs strongly on the surface of BN nanocage (d orientation) the dipole moment of system increases significantly from original state.

An important factor for the evaluation of the performance of gas sensor was the recovery time of the gas sensing material. To better understanding of sensitivity of the nanocage toward to MCP as a sensor device, the recovery time of A-a, A-d, B-a, B-d, C-a and C-d adsorption models was calculated by $\tau=V_{0}^{-1} \exp ^{(-\mathrm{Ead} / \mathrm{kT})}$, where temperature was $298.15 \mathrm{~K}, \mathrm{k}$ was the Boltzmann's constant $(\mathrm{k}=0.00198$ $\mathrm{Kcal} / \mathrm{mol})$, and $v_{0}$ was the attempt frequency $\left(v_{0}=10^{12} \mathrm{~s}^{-1}\right)$. According to this equation, the average 
recovery time of the A-a, A-d, B-a, B-d, C-a and C-d models were $2.12 \times 10^{-6}, 1.53 \times 10^{22}, 5.65 \times 10^{7}, 2.51 \times 10^{23}$, $3.39 \times 10^{4}$ and $1.30 \times 10^{15} \mathrm{~s}$, respectively. These results demonstrated that the interaction between the MCP molecule and B12N12 at the B-d model was strongest, and at the A-a model was weakest. Therefore the pristine B12N12 nanocluster (A-a model) with lower recovery time was suitable for making sensor for MCP molecule and the Ni functionalized B12N12 (B-d model) with most recovery time was favorable for making adsorbent for the MCP molecule [56-57]. In addition, our results revealed that the adsorption of the MCP from S site on the surface of BN nanocluster was the best candidate to make the MCP sensors.

The amounts of thermodynamic parameters $(\Delta \mathrm{H}$ and $\Delta \mathrm{G})$ for all the adsorption models were negative, which indicated that the adsorption of the MCP on the surface pristine, Ni and Pd functionalized B12N12 were an exothermic and spontaneous process at gas phase. The $\Delta \mathrm{H}$ and $\Delta \mathrm{G}$ values for B-d adsorption model were more than the other models and so the adsorption of MCP from $\mathrm{N}$ head on the surface of $\mathrm{Ni}$ and B12N12 was more stable and spontaneous than other models. The infrared (IR) spectrum for A-a, A-d, B-a, B-d, C-a and C-d adsorption models were produced from outputs of thermodynamic calculations, and the IR results are shown in the Figure S4 supplementary data. Comparison results demonstrated that a maximum peak was shown in the frequency $1500 \mathrm{~cm}^{-1}$. The altitude of this peak in the $\mathrm{Ni}$ and $\mathrm{Pd}$ functionalized model was more than pristine model.

To investigate the deformation of structures of MCP and nanocluster in the MCP/nanocluster complex the deformation energy of MCP and nanocluster was calculated using Equation 7 and 8.

$$
\begin{gathered}
E_{\text {def-B12N12 }}=E_{B 12 N 12 \text { pure }}-E_{B 12 N 12 \text { in complex }} \\
E_{d e f-M P Y}=E_{M P Y \text { pure }}-E_{M P Y \text { in complex }}
\end{gathered}
$$

Where $E_{\mathrm{B} 12 \mathrm{~N} 12 \text { in complex }}$ is the total energy of B12N12 in the B12N12/MCP complex when MCP is absent oneself, and $\mathrm{E}_{\mathrm{MCP}}$ in complex is the total energy of MCP molecule in the B12N12/MCP complex when B12N12 is absent oneself. According to obtained results in Table 1, the deformation energy of B12N12 and MCP for all adsorption is negative. The negative value of deformation energy displays that the deformation process of molecule is spontaneous and stable. As seen in Table 1, deformation energy of the B12N12 at the A-a and A-d adsorption models was more than other models, which means the curvature in the geometry of B12N12 in these models was significantly larger than other models. On the other hand, the deformation energy of MCP at all adsorption models was in range -0.31 to $-1.16 \mathrm{Kcal} / \mathrm{mole}$, and it was lower than the B12N12 nanocluster.

To investigate the solvent effect on the adsorption of MCP on the surface of pristine and $\mathrm{Ni}$ and $\mathrm{Pd}$ functionalized B12N12, by using the polarizable continuum model (PCM) the variation of Gibbs free 
energy of system in water and ethanol phase was calculated, and the results are listed in Table 1. Inspection of results revealed that the $\Delta \mathrm{G}_{\text {(water) }}$ and $\Delta \mathrm{G}_{\text {(ethanol) }}$ for $\mathrm{A}-\mathrm{a}, \mathrm{A}$-d (the adsorption MCP on pristine model B12N12) are positive and at the other models are negative. The negative values of $\Delta \mathrm{G}_{\text {(water) }}$ and $\Delta \mathrm{G}_{(\text {ethanol) }}$ demonstrate that the adsorption of MCP in the presence of water and ethanol was spontaneous. It was confirmed that, the adsorption of MCP on the surface of Ni and Pd functionalized B12N12 were thermodynamically feasible at the ambient conditions. The order of $\Delta \mathrm{G}_{(\mathrm{sol})}$ of A-d, B-d and C-d at the presence of water and ethanol solvent was B-d>C-d>A-d. It is notable that the Ni functionalized B12N12 nanocage was a good candidate to adsorb MCP in the gas, water, and ethanol phase, and the order of $\Delta \mathrm{G}$ values for B-d adsorption model was $\Delta \mathrm{G}_{\text {gas }}(-33.50 \mathrm{kcal} / \mathrm{mol})>\Delta \mathrm{G}_{\text {Ethanol }}(-22.84 \mathrm{kcal} / \mathrm{mol})>\Delta \mathrm{G}_{\text {water }}(-21.05$ $\mathrm{kcal} / \mathrm{mol})$. The order of $\Delta \mathrm{G}$ values for $\mathrm{C}$-d adsorption model was $\Delta \mathrm{G}_{\text {gas }}(-23.62 \mathrm{kcal} / \mathrm{mol})>\Delta \mathrm{G}_{\text {water }}(-14.04$ $\mathrm{kcal} / \mathrm{mol})>\Delta \mathrm{G}_{\text {Ethanol }}(-13.77 \mathrm{kcal} / \mathrm{mol})$. Comparisons of results confirmed that the adsorption process in the gas phase was more favorable than water and ethanol phase, because at the presence of solvent, due to repulsion interaction between the MCP with solvent, the adsorption process becomes weak.

\section{HOMO and LUMO orbital quantum parameters}

To understand the electronical properties of system, the highest occupied molecular orbital (HOMO), the lowest unoccupied molecular orbital (LUMO), energy gap ( $\mathrm{E}_{\text {gap }}$ ), the partial density of state (PDOS), electronic chemical potential $(\mu)$, global hardness $(\eta)$, electrophilicity $(\omega)$ and total charge transfer parameters $(\Delta \mathrm{N})$ are calculated and results are listed in Table 2. The calculated results of the HOMO-LUMO and PDOS plots for all the adsorption models are illustrated in Figures 3 and 4. As seen in Figure 3, the HOMO orbital of MCP adsorption on pristine nanocluster (A-a and A-d models) was delocalized uniformly around B12N12 surface, whereas with functionalizing Ni and Pd atoms the most HOMO orbital density was localized around adsorption position. The LUMO orbital density of all adsorption models were only delocalized around the MCP molecule. Similar HOMO orbital, with functionalizing Ni and Pd atoms the most LUMO orbital density was distributed around the adsorption and functionalization site, indicated the electron conduction through this system. From HOMO and LUMO outputs the partial density of states (PDOS) plots for adsorption MCP on the surface of B12N12 nanocluster for A-a, A-d, B-a, B-d, C-a and C-d models were calculated in interval -15 to $0 \mathrm{eV}$ using the Gaussum software (Figure 4). Based on the results of the PDOS plots, it was found that the partial density of the state for MCP was greater than that of the B12N12. On the other hand, with functionalizing $\mathrm{Ni}$ and $\mathrm{Pd}$ atoms a new state was appeared within the gap energy above the valence level, which mainly begins from the contribution of MCP molecule. The HOMO-LUMO orbital analysis demonstrated that this level was located on the MCP molecule. The gap energy of pristine B12N12 was 5.94 and with functionalizing $\mathrm{Ni}$ and Pd atoms decreased significantly to 
3.41 and $3.54 \mathrm{eV}$, respectively, due to appear new state between gap energy region. The gap energy of the A-a, A-d, B-a, B-d, C-a, and C-d models is 5.25, 3.86, 4.04, 3.23, 4.38, and $3.65 \mathrm{eV}$, respectively.

Table 2. Quantum parameters of mercaptopyridine adsorption on the surface of pristine and Ni functionalized B12N12

\begin{tabular}{|c|c|c|c|c|c|c|c|c|c|}
\hline & $\mathbf{A}$ & $\mathbf{A - a}$ & $\mathbf{A - d}$ & $\mathbf{B}$ & $\mathbf{B - a}$ & $\mathbf{B}-\mathbf{d}$ & $\mathbf{C}$ & $\mathbf{C}-\mathbf{a}$ & C-d \\
\hline $\mathrm{E}_{\mathrm{LUMM} / \mathrm{eV}}$ & $\bullet$ & -2.05 & -2.97 & $\bullet$ & -2.13 & -2.48 & $\bullet$ & -1.96 & -2.24 \\
\hline $\mathrm{E}_{\mathrm{HOMO} / \mathrm{eV}}$ & -7.87 & -7.33 & -6.82 & -6.53 & -6.21 & -5.71 & -6.58 & -6.34 & -5.89 \\
\hline $\mathrm{E}_{\mathrm{g} / \mathrm{eV}}$ & 5.94 & 5.28 & 3.86 & 3.41 & 4.08 & 3.23 & 3.54 & 4.38 & 3.65 \\
\hline $\mathrm{V}_{\mathrm{eV}}$ & 2.97 & 2.65 & 1.93 & 1.70 & 2.04 & 1.62 & 1.77 & 2.19 & 1.82 \\
\hline$\mu / \mathrm{eV}$ & -4.90 & -4.69 & -4.90 & -4.83 & -4.17 & -4.09 & -4.81 & -4.15 & -4.06 \\
\hline$\omega / \mathrm{eV}$ & 4.06 & 4.15 & 6.22 & 6.84 & 4.26 & 5.18 & 6.50 & 7.86 & 4.52 \\
\hline$\Delta \mathrm{N}$ & 1.65 & 1.77 & 2.54 & 2.84 & 2.04 & 2.52 & 2.72 & 1.89 & 2.23 \\
\hline$\Delta \rho_{\mathrm{NBO}}$ & - & 0.40 & 0.06 & - & 0.23 & 0.03 & - & 0.20 & 0.02 \\
\hline$\Delta \rho_{\text {Mulliken }}$ & - & 0.31 & 0.04 & - & 0.24 & 0.06 & - & 0.24 & 0.10 \\
\hline
\end{tabular}

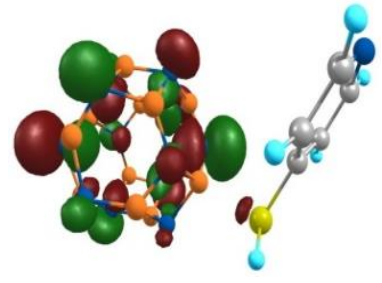

A-a-H

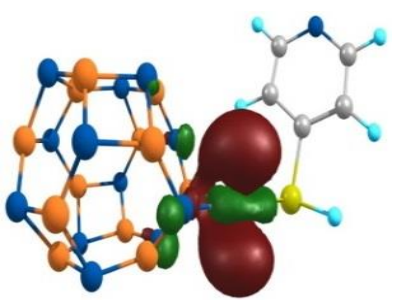

B-a-H

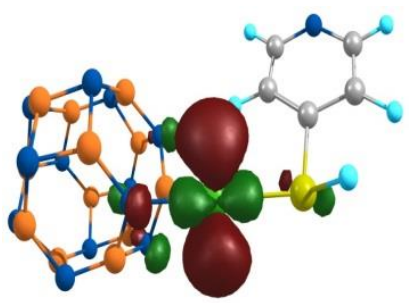

C-a-H

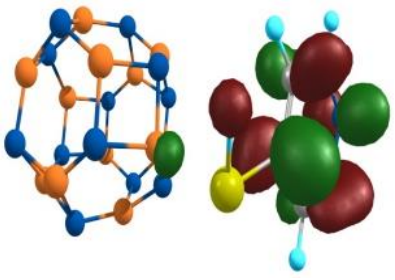

A-a-L

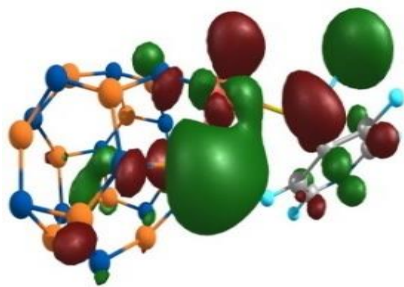

B-a-L

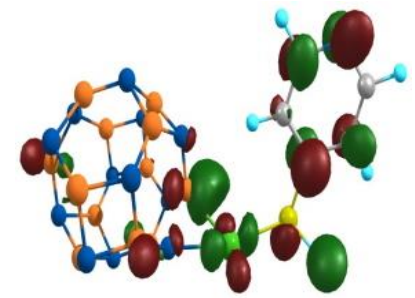

C-a-L

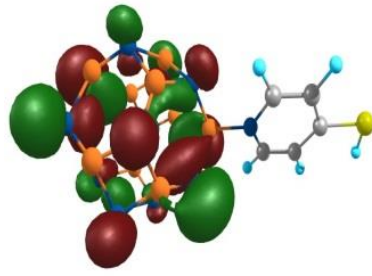

A-d-H

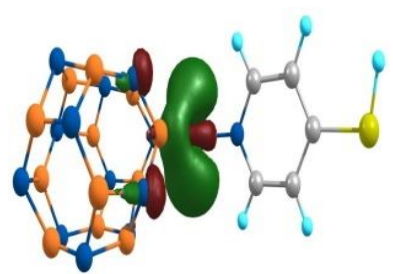

B-d-H

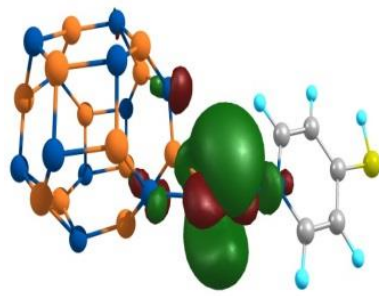

C-d-H

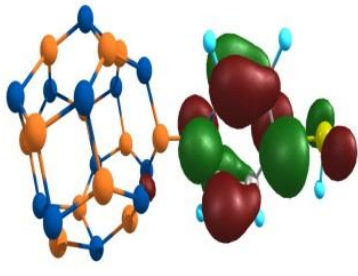

A-d-L

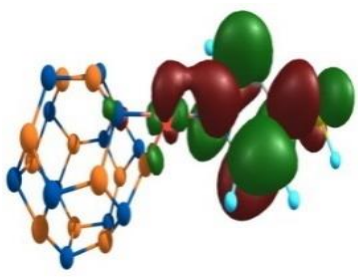

B-d-L

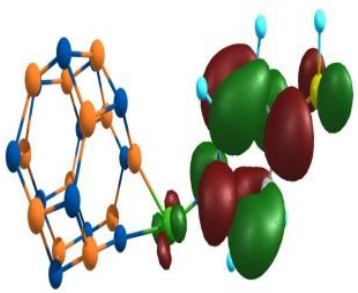

C-d-L

Figure 3. The HOMO-LUMO orbitals of MCP molecule on the surface of the pristine and Ni, Pd functionalized B12N12 nano cage at the A-a to C-d adsorption models 


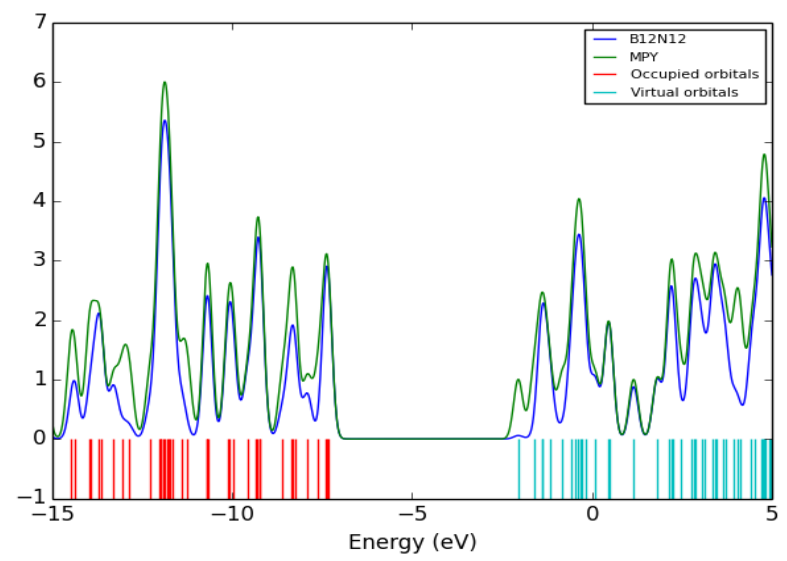

A-a

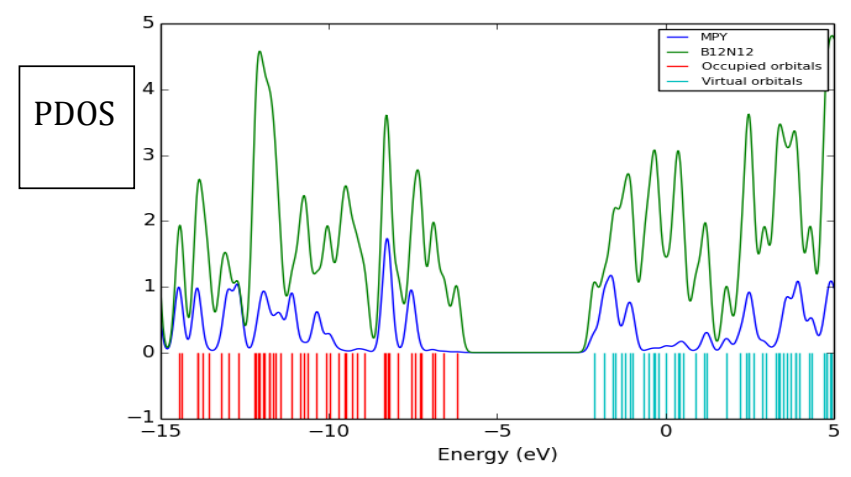

B-a

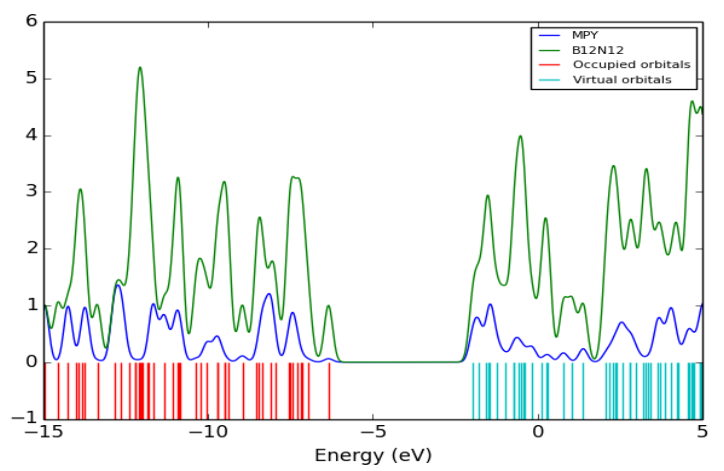

C-a

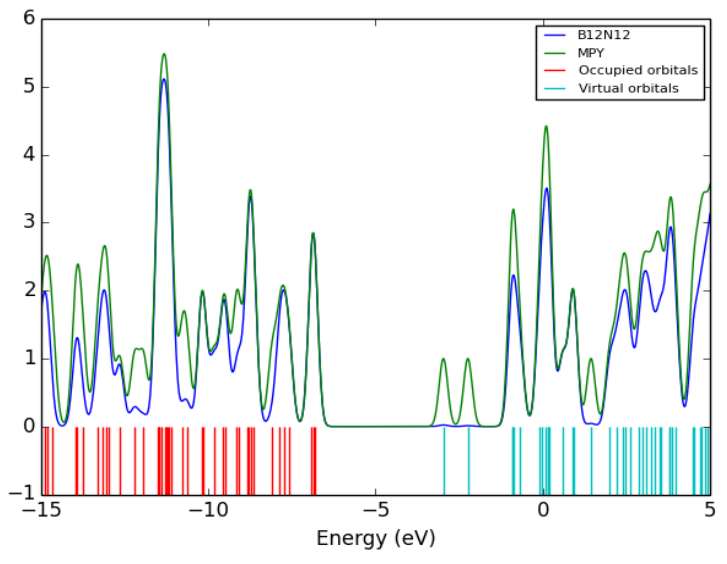

A-d

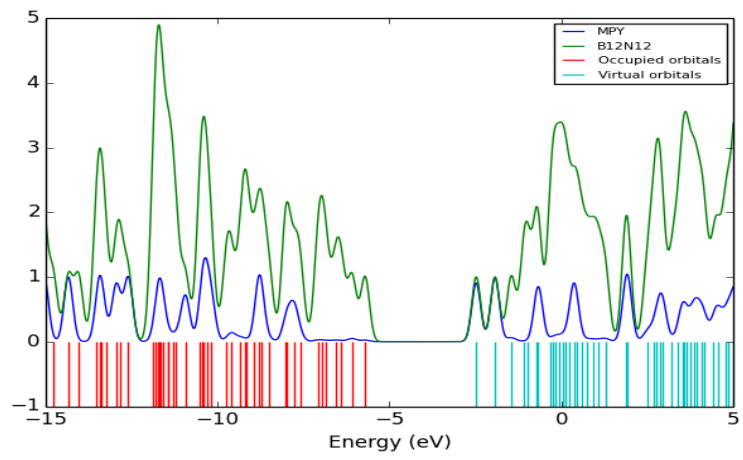

B-d

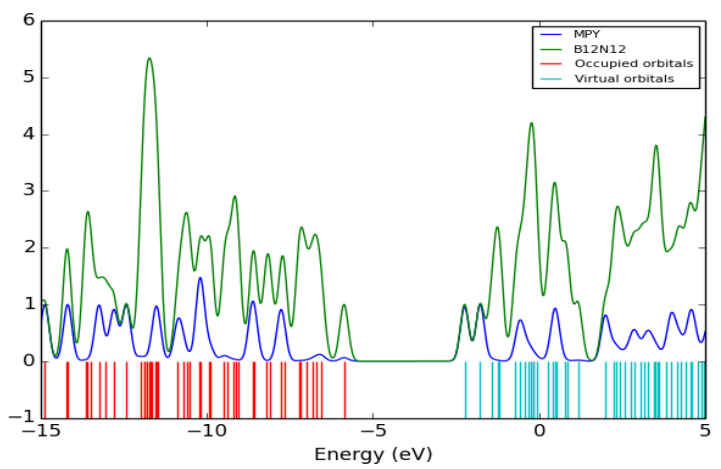

C-d

Figure 4. The PDOS plots of MCP molecule on the surface of the pristine and Ni, Pd functionalized B12N12 nano cage at the A-a to C-d adsorption models 
Comparison results indicated that, with adsorbing the MCP and functionalizing the Ni and Pd atoms the gap energy of MCP/B12N12 complex altered significantly from the original states. The conductivity of system (according to equation of $\delta \propto \exp p^{-E_{g a p} / K T}$ ) increased significantly from the original state. Thereby, with functionalizing $\mathrm{Ni}$ and $\mathrm{Pd}$ atoms the sensitivity and conductivity of the B12N12 nanocluster increased with MCP adsorption, and this property was suitable to make the sensor for detecting MCP molecule. The global hardness is one of the important parameter used to determine the resistance chemical systems towards deformation of the electron cloud under small perturbation encountered during the chemical process. The global hardness of all adsorption models was at the range of 1.62-2.97 eV. Inspection of the results indicated that with functionalizing the $\mathrm{Ni}$ and $\mathrm{Pd}$ atoms, the global hardness of the B12N12 nanocage decreased significantly from $2.97 \mathrm{eV}$ to $1.7 \mathrm{eV}$, as a result the reactivity of nanocluster increased significantly from the pristine state. When the MCP molecule approached from $\mathrm{N}$ site on the surface of nanocage, the global hardness of the MCP/B12N12 complex decreased significantly from the original state. The global hardness of A-d, B-d and C-d was in order of A-d $(1.93 \mathrm{eV})>\mathrm{C}-\mathrm{d}(1.82 \mathrm{eV})>\mathrm{B}-\mathrm{d}(1.62 \mathrm{eV})$. The chemical potential $(\mu)$ and electrophilicity index $(\omega)$ of $\mathrm{MCP} / \mathrm{B} 12 \mathrm{~N} 12$ complex were found to be at the range of $-4.06--4.90 \mathrm{eV}$ and $4.06-7.86 \mathrm{eV}$, respectively. The chemical potential of the Ni and Pd functionalized B12N12 nanocage was lower than the pristine models, so the reactivity of these models was greater than that of the pristine state.

The total charge transfer parameters of A-a, A-d, B-a, B-d, C-a and C-d adsorption models were positive at the range of 1.77-2.54. Moreover the $\Delta \rho_{\mathrm{NBO}}$ and $\Delta \rho_{\text {Mullikan }}$ charges for all adsorption models were at the range of $0.02-0.40|\mathrm{e}|$ and $0.04-0.31|\mathrm{e}|$. The positive values of the $\Delta \mathrm{N}, \Delta \rho_{\mathrm{NBO}}$ and $\Delta \rho_{\text {Mullikan }}$ indicated that in all the adsorption models, the charge transfer occurred from MCP molecule toward the nanocluster surface as the charge density around adsorption position of nanocluster increased. This result was in agreement with the HOMO and LUMO results.

Thus, in brief, it can be stated that the adsorption MCP on the surface of Ni, Pd functionalized B12N12 nanocage change electronic properties of system and this property is very favorable to making nano sensor and adsorbent for MCP molecule. To further realize the charge distribution on the surface of the MCP/B12N12 nanocluster, the molecular electrostatic potential (MEP) plots for all adsorption models are calculated and the results are shown in Figure 5. Comparison results indicated that, the maximum positive electrostatic potential occurred around the MCP position and negative electrostatic potential occurred around the nanocluster surface. With functionalizing the $\mathrm{Ni}$ and $\mathrm{Pd}$ atoms, the positive electrostatic potential around the MCP position increased from pristine model. This result was similar to the HOMO-LUMO orbital distributions. 


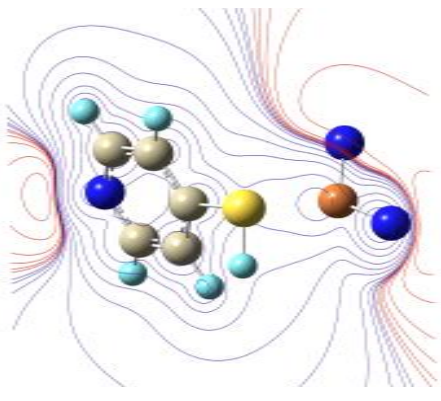

A-a

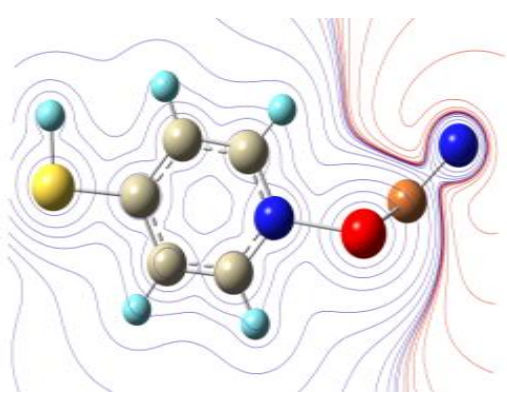

B-d

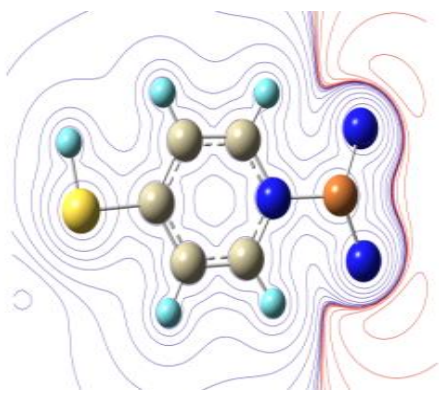

A-d

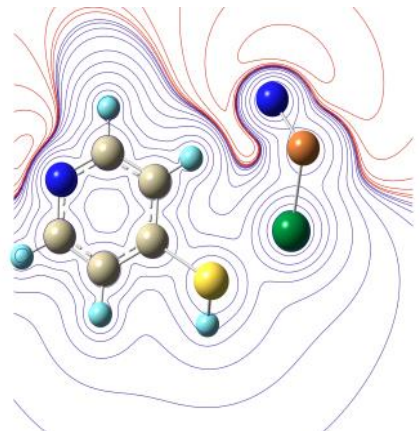

C-a

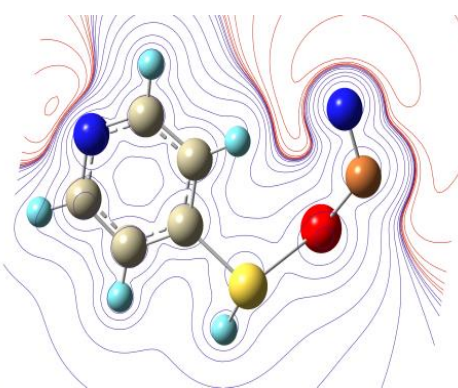

B-a

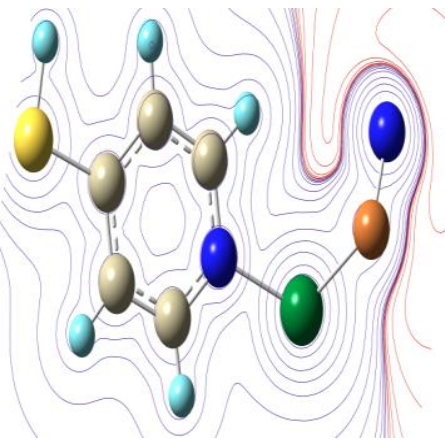

C-d

Figure 5. The MEP plots of MCP molecule on the surface of the pristine and $\mathrm{Ni}, \mathrm{Pd}$ functionalized B12N12 nano cage at the A-a to C-d adsorption models

\section{Quantum theory of atom in molecule (QTAIM) and reduced density gradient (RDG)}

Bader's quantum theory of atoms in molecules (QTAIM) [58] analysis was performed with the AIM all package [59] to study the bonding nature and strength of the interactions between the MCP and B12N12 nanocluster. For this aim, the electron densities $(\rho)$ and Laplacian of electron densities $\left(\nabla^{2} \rho\right)$, the potential energy $\left(\mathrm{V}_{\mathrm{BCP}}\right)$, the total electronic energy $\left(\mathrm{H}_{\mathrm{BCP}}\right)$, and the kinetic energy $\left(\mathrm{G}_{\mathrm{BCP}}\right)$ at bond critical point (BCP) of MCP-B12N12 were calculated (Table 4 and Figure 6). According to the Bader theory, the negative values of $\nabla^{2} \rho$ and $\mathrm{H}$ values refer to strong interaction (strong covalent bond), the positive values of $\nabla^{2} \rho$ and $\mathrm{H}$ denote the weak covalent interactions (strong electrostatic bond), and the negative value of $\mathrm{H}$ and positive value of $\nabla^{2} \rho$ refer to medium strength or partially covalent bond. As demonstrated in Table 4, the values of the $\nabla^{2} \rho$ and $\mathrm{H}$ for A-a and B-d were positive, showing the weak covalent interactions (strong electrostatic).

One of the important topological parameter to determine the interaction strength is the charge density $\left(\rho_{\mathrm{BCP}}\right)$. As seen in Table 4, the $\rho_{\mathrm{BCP}}$ for C-d (0.1649) and B-d (0.0870) was significantly larger than those other adsorption models. On the other hand, absolute values of the $\nabla^{2} \rho$, G $\mathrm{BCP}$, and $\mathrm{V}_{\mathrm{BCP}}$ for C-d and B-d model was greater than the other models. These results demonstrated that, the interaction of the MCP 
from $\mathrm{N}$ head on the surface of the $\mathrm{Ni}$ and Pd functionalized BN nanocluster was stronger than other models which confirmed the trend of the adsorption energy.

Table 4. Topological (Atom in molecule) parameters of mercaptopyridine adsorption on the surface of pristine and Ni functionalized B12N12

\begin{tabular}{|c|c|c|c|c|c|}
\hline & $\boldsymbol{\rho}_{(\mathbf{B C P})}$ & $\nabla^{2} \boldsymbol{\rho}_{(\mathbf{B C P})}$ & $\mathbf{G}_{\text {(BCP) }}$ & $\mathbf{H}_{\text {(BCP) }}$ & $-\mathbf{V}_{\text {(BCP) }}$ \\
\hline $\mathrm{A}(\mathrm{a})$ & 0.0639 & 0.0086 & 0.0241 & 0.0262 & 0.0403 \\
\hline $\mathrm{A}(\mathrm{d})$ & 0.0154 & 0.0309 & 0.0079 & -0.0023 & 0.0082 \\
\hline $\mathrm{B}(\mathrm{a})$ & 0.0654 & 0.3072 & 0.0829 & -0.0062 & 0.0891 \\
\hline $\mathrm{B}(\mathrm{d})$ & 0.0870 & 0.2921 & 0.0872 & 0.0142 & 0.1014 \\
\hline $\mathrm{C}(\mathrm{a})$ & 0.0639 & 0.2059 & 0.0661 & -0.0146 & 0.0807 \\
\hline $\mathrm{C}(\mathrm{d})$ & 0.1649 & 0.1657 & 0.1932 & -0.1512 & 0.3445 \\
\hline
\end{tabular}

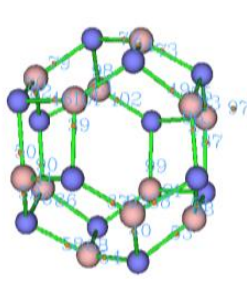

A-a

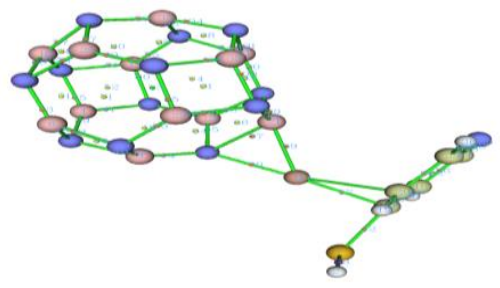

B-d

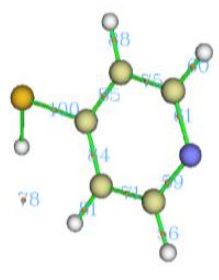

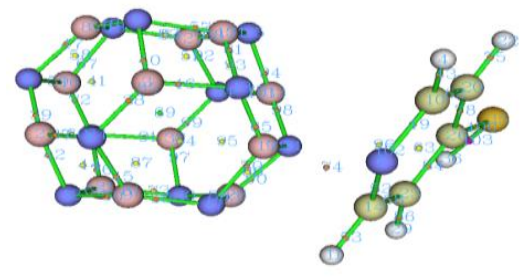

A-d

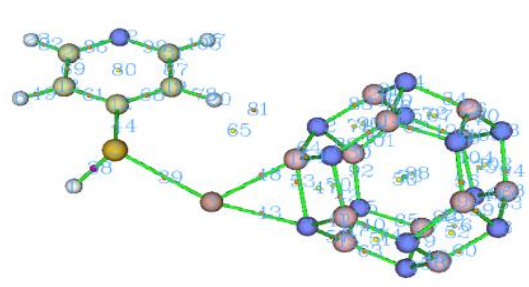

C-a

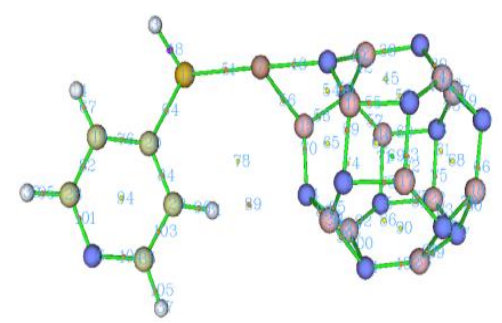

B-a

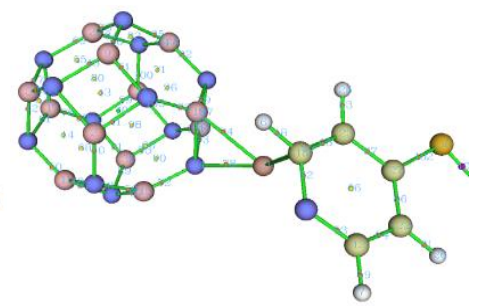

C-d

Figure 6. The atom in molecule of MCP molecule on the surface of the pristine and Ni, Pd functionalized B12N12 nano cage at the $\mathrm{A}$-a to $\mathrm{C}$ - $\mathrm{d}$ adsorption models

To further understand the intramolecular interactions (van der Waals between MCP....B12N12) the non-covalent interaction index (NCI) was calculated. The reduced density gradient (RDG) was defined [60].

$$
R D G(r)=\frac{1}{2\left(3 \pi^{2}\right)^{1 / 3}} \frac{|\nabla \rho(r)|}{\rho(r)^{4 / 3}}
$$

Non-covalent interactions were characterized using the small values of RDG. The product between the electron density $\rho(\mathrm{r})$ and the sign of the second lowest eigenvalues of the electron density hessian 
matrix $\left(\lambda_{2}\right)$ was proposed as a tool to distinguish the different types of interactions. The scatter graphs of RDG versus sign $\left(\lambda_{2}\right) \rho(\mathrm{r})$ for all adsorption models are shown in Figure 7. The X-axis and Y axis are sign $\left(\lambda_{2}\right) \rho(r)$ and RDG function, respectively. The sign $\left(\lambda_{2}\right) \rho(r)$ was utilized to distinguish the bonded $\left(\lambda_{2}<0\right)$ interactions from the nonbonding $\left(\lambda_{2}>0\right)$ interactions. In the RDG scatter, the red color circle showed the attractive interactions, blue color circle denotes strong repulsive interactions and green circle implies low electron density, corresponding to the Van der walls interactions. It was clearly observed that, in the all adsorption model, more electron density localized in $\lambda_{2}<0$ and $\lambda_{2}=0$ regions, and so the interaction between MCP and nanocage is Van der walls type. The results of the RDG scatter revealed that the interaction of MCP and Ni and Pd functionalized B12N12 (C-d and B-d models) were stronger than other pristine model. This result was in a good agreement with adsorption energy and AIM result.

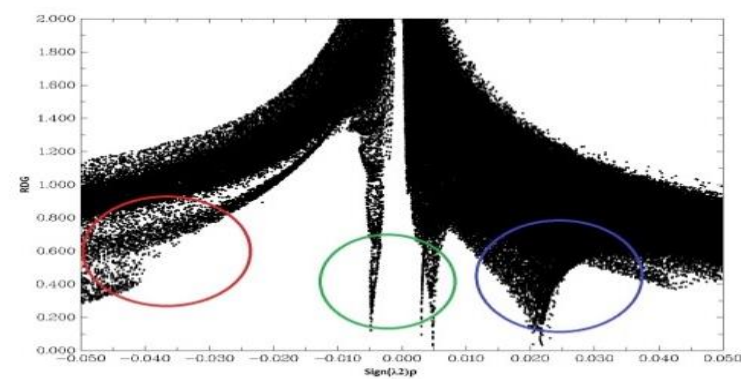

A-a

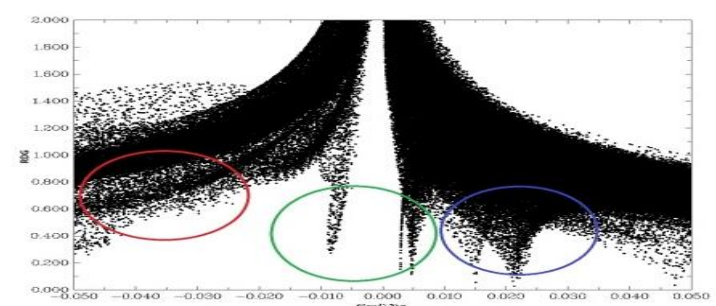

B-a

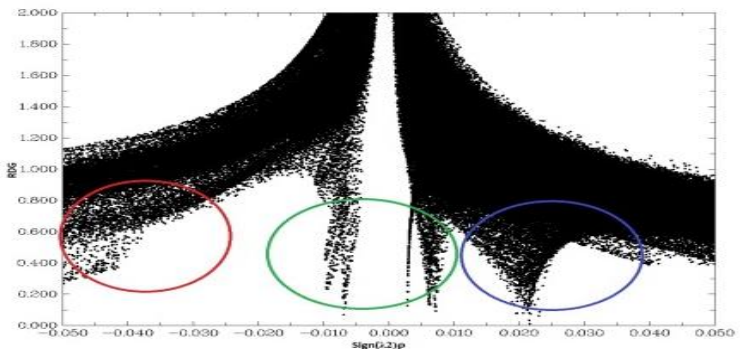

C-a

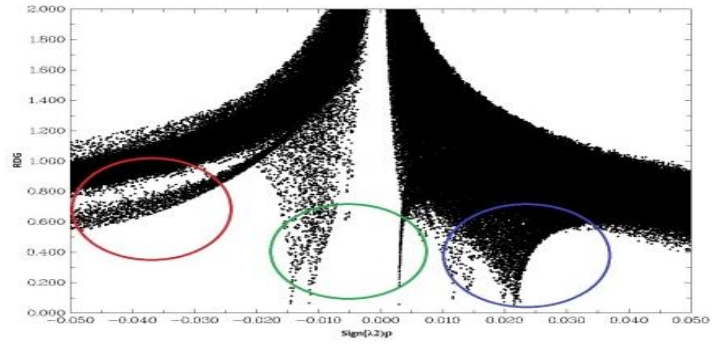

A-d

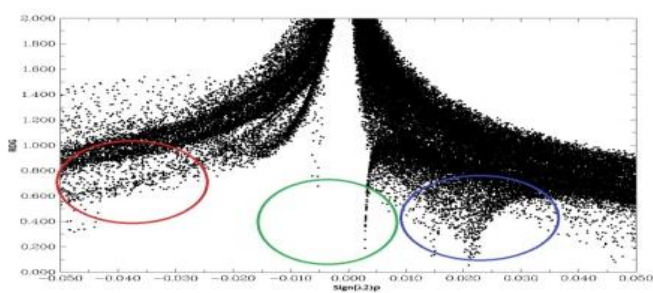

B-d

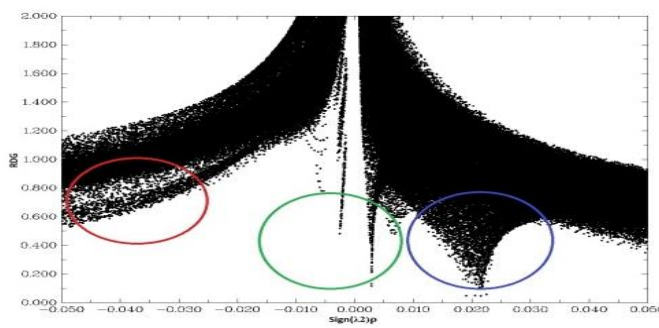

C-d

Figure 7. The RDG plots of MCP molecule on the surface of the pristine and Ni, Pd functionalized B12N12 nano cage at the A-a to $\mathrm{C}$ - $\mathrm{d}$ adsorption models 


\section{Excited state and UV-visible}

One of the most important methods in quantum chemistry for the prediction of effective parameters in the performance of biochemical systems is the TD-DFT method. The TD-DFT method is used to investigate the electronic levels of molecules, fluorescence spectrum, and behavior of molecule at excited state [61].

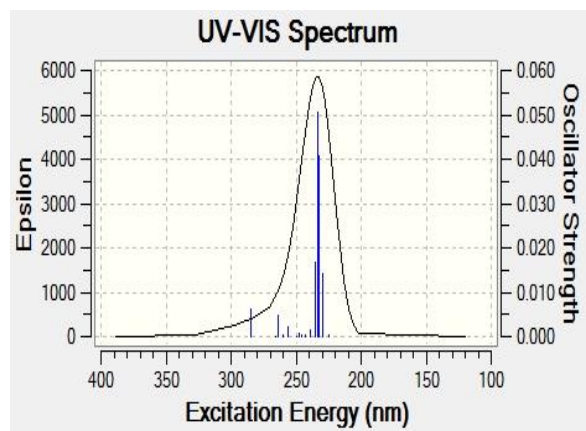

A-a

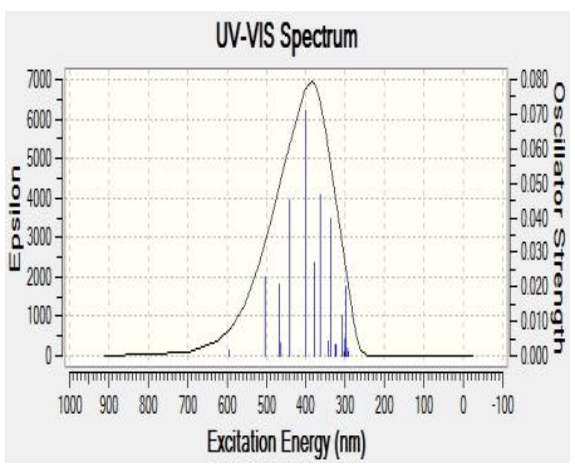

B-d

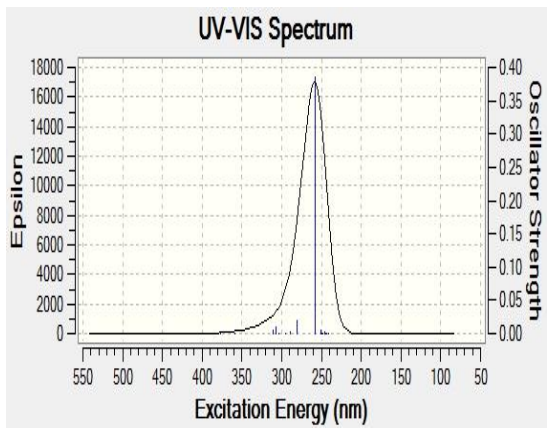

A-d

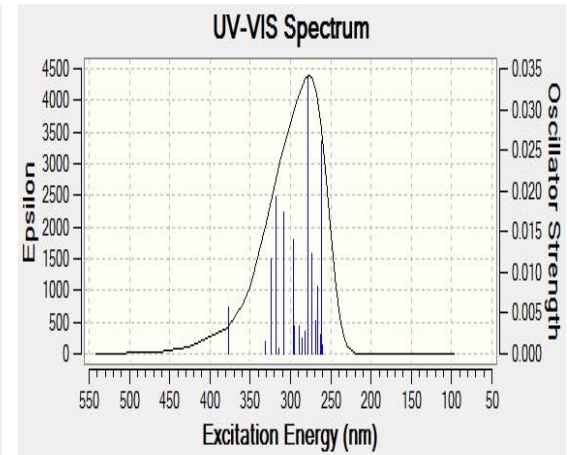

C-a

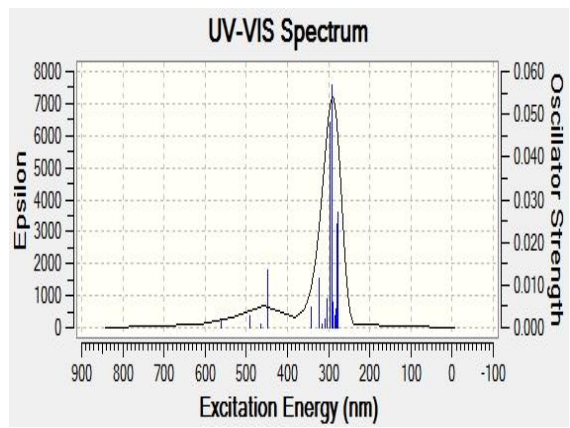

B-a

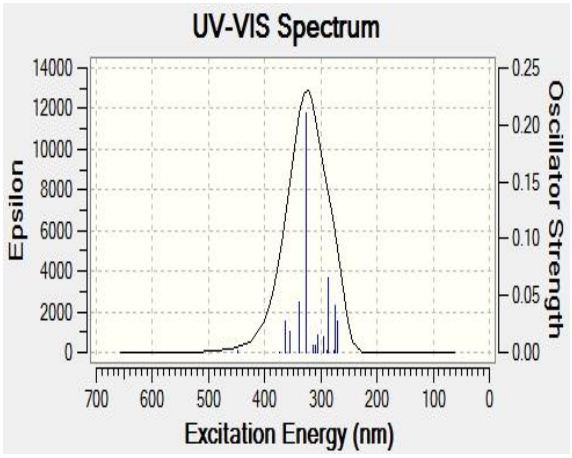

C-d

Figure 8. The UV-Vis spectrums of MCP molecule on the surface of the pristine and Ni, Pd functionalized B12N12 nano cage at the $\mathrm{A}$-a to $\mathrm{C}$ - $\mathrm{d}$ adsorption models

The fluorescence spectrums are used for detecting drugs carriers in bio systems and understand the mechanism of electron transfer at excited state in biochemical systems [62-63]. The UV-visible spectra at the 30 excited states for all adsorption models in the gas phase are calculated using the TDB3LYP/Lanl2DZ method. The calculated results are listed in Table 5 and the UV-visible spectrum is shown in Figure 8. Comparison results demonstrate that the value of $\lambda_{\max }$ for all adsorption models is in range 200 to $400 \mathrm{~nm}$, and this value is in the UV region. As can be seen from Table 5, the $\lambda_{\max }$ values for A-a, A-d are 233.31 and $258.42 \mathrm{~nm}$ is observed at oscillator strength $\mathrm{f}=0.0504$ and 0.3844 respectively. This maximum wavelength for A-a and A-d is due to charge transfer of electron into the excited state $\mathrm{H}$ $2 \rightarrow \mathrm{L}+1(34.30 \%)$ and $\mathrm{H}-6 \rightarrow \mathrm{L}(89.53 \%)$ and is mainly focused on double bonds $(\mathrm{C}=\mathrm{C})$ of pyridine ring and sulfur atom. After adsorption of MCP on the surface of Ni functionalized B12N12 at the B-a and B-d 
models the strong absorption band in electronic absorption spectrum is shown in the $\lambda_{\max }=291.17$ and $400.05 \mathrm{~nm}$ with the oscillator strength $\mathrm{f}=0.0567$ and 0.0711 respectively. In the B-a and B-d model the $\lambda_{\max }$ is due to charge transfer of electron into the excited state $\mathrm{H}-1 \rightarrow \mathrm{L}+3(35.34 \%)$ and $\mathrm{H}-1 \rightarrow \mathrm{L}(37.24 \%)$. Whereas in the C-a and C-d models with functionalizing Pd atom the $\lambda_{\max }$ is shown in 317.96 and 326.43 $\mathrm{nm}$ with the oscillator strength $\mathrm{f}=0.0194$ and 0.2109 , respectively. In these models the charge transfer of electron occurred into the excited state $\mathrm{H}-3 \rightarrow \mathrm{L}(53.95 \%)$ and $\mathrm{H}-3 \rightarrow \mathrm{L}$ (55.61\%). Noticeably, the $\lambda_{\max }$ for the strong absorption band in electronic absorption spectrum of A-a, B-a, C-a, A-d, B-d and C-d adsorption models are in order: $\left(\lambda_{\max } \mathrm{C}-\mathrm{a}>\lambda_{\max } \mathrm{B}-\mathrm{a}>\lambda_{\max } \mathrm{A}-\mathrm{a}\right)$ and $\left(\lambda_{\max } \mathrm{B}-\mathrm{d}>\lambda_{\max } \mathrm{C}-\mathrm{d}>\lambda_{\max } \mathrm{A}-\mathrm{d}\right)$. This result confirms that the $\mathrm{B}-\mathrm{d}$ model with the most value of $\lambda_{\max }$ has the most dipole moment and the high effectiveness as an electron recipient and absorbent in the UV area show that that the $\mathrm{Ni}$ and $\mathrm{Pd} \&$ B12N12 is an absorbent acceptor along with different kinds of organic donor and MCP molecule.

Table 5. UV-visible parameters of mercaptopyridine adsorption on the surface of pristine and Ni functionalized B12N12

\begin{tabular}{|c|c|c|c|c|}
\hline & Transition & $\lambda$ & $f$ & Transition\% \\
\hline \multirow[t]{4}{*}{$A-a$} & $\mathrm{H}-1 \rightarrow \mathrm{L}+4$ & 235.30 & 0.0168 & $43.11 \%$ \\
\hline & $\mathrm{H}-2 \rightarrow \mathrm{L}+1$ & 233.31 & 0.0504 & $34.30 \%$ \\
\hline & $\mathrm{H}-1 \rightarrow \mathrm{L}+1$ & 232.45 & 0.0408 & $35.65 \%$ \\
\hline & $\mathrm{H}-5 \rightarrow \mathrm{L}$ & 229.93 & 0.0142 & $18.33 \%$ \\
\hline \multirow[t]{3}{*}{ A-d } & $\mathrm{H}-2 \rightarrow \mathrm{L}+4$ & 234.97 & 0.0140 & $16.87 \%$ \\
\hline & $\mathrm{H}-5 \rightarrow \mathrm{L}$ & 280.82 & 0.0187 & $97.39 \%$ \\
\hline & $\mathrm{H}-6 \rightarrow \mathrm{L}$ & 258.42 & 0.3844 & $89.53 \%$ \\
\hline \multirow[t]{6}{*}{ B-a } & $\mathrm{H}-3 \rightarrow \mathrm{L}$ & 447.42 & 0.0135 & $38.82 \%$ \\
\hline & $\mathrm{H} \rightarrow \mathrm{L}+3$ & 323.86 & 0.0114 & $61.51 \%$ \\
\hline & $\mathrm{H}-4 \rightarrow \mathrm{L}$ & 297.58 & 0.0479 & $23.12 \%$ \\
\hline & $\mathrm{H}-1 \rightarrow \mathrm{L}+3$ & 291.17 & 0.0567 & $35.34 \%$ \\
\hline & $\mathrm{H}-5 \rightarrow \mathrm{L}$ & 278.65 & 0.0242 & $18.73 \%$ \\
\hline & $\mathrm{H}-7 \rightarrow \mathrm{L}+1$ & 277.07 & 0.0270 & $31.56 \%$ \\
\hline \multirow[t]{5}{*}{ B-d } & $\mathrm{H} \rightarrow \mathrm{L}+2$ & 468.57 & 0.0208 & $26.88 \%$ \\
\hline & $\mathrm{H}-3 \rightarrow \mathrm{L}$ & 441.14 & 0.0448 & $30.15 \%$ \\
\hline & $\mathrm{H}-1 \rightarrow \mathrm{L}$ & 400.05 & 0.0711 & $37.24 \%$ \\
\hline & $\mathrm{H}-2 \rightarrow \mathrm{L}+2$ & 378.54 & 0.0272 & $39.47 \%$ \\
\hline & $\mathrm{H}-2 \rightarrow \mathrm{L}+1$ & 335.45 & 0.0395 & $72.93 \%$ \\
\hline \multirow[t]{3}{*}{$\mathrm{C}-\mathrm{a}$} & $\mathrm{H} \rightarrow \mathrm{L}+1$ & 323.73 & 0.0116 & $69.57 \%$ \\
\hline & $\mathrm{H}-3 \rightarrow \mathrm{L}$ & 317.96 & 0.0194 & $53.95 \%$ \\
\hline & $\mathrm{H} \rightarrow \mathrm{L}+2$ & 307.83 & 0.0174 & $57.77 \%$ \\
\hline \multirow[t]{6}{*}{ C-d } & $\mathrm{H} \rightarrow \mathrm{L}+2$ & 364.37 & 0.0280 & $73.68 \%$ \\
\hline & $\mathrm{H}-1 \rightarrow \mathrm{L}$ & 354.16 & 0.0183 & $58.14 \%$ \\
\hline & $\mathrm{H}-2 \rightarrow \mathrm{L}$ & 338.42 & 0.0447 & $53.87 \%$ \\
\hline & $\mathrm{H}-3 \rightarrow \mathrm{L}$ & 326.43 & 0.2109 & $55.61 \%$ \\
\hline & $\mathrm{H} \rightarrow \mathrm{L}+4$ & 305.41 & 0.0146 & $40.03 \%$ \\
\hline & $\mathrm{H}-3 \rightarrow \mathrm{L}+2$ & 295.25 & 0.0133 & $54.29 \%$ \\
\hline
\end{tabular}




\section{Natural bond orbital analysis}

To further study of charge transfer or conjugative interaction between MCP/B12N12 complex we use the natural bond orbital (NBO) analysis, this method is an effective tool to investigate the chemical interpretation of hyper-conjugative interaction and electron density transfer from the filled lone pair electron [64]. For this aim the stabilization energy $\left(E^{2}\right)$ associated with the delocalization donor (i) to acceptor (j) orbitals is determined by using follow equation:

$$
E^{2}=q_{i} \frac{F_{i j}^{2}}{\varepsilon_{j}-\varepsilon_{i}}
$$

Where $q_{i}$ is donor orbital occupancy, ${ }^{\varepsilon_{i}}$ and ${ }^{\varepsilon_{j}}$ are orbital energies and $\mathrm{F}_{\mathrm{ij}}$ is the off-diagonal NBO Fock matrix element. The stabilization energy $\mathrm{E}^{(2)}$ is proportional to the NBO interaction intensities. The calculated results of $\mathrm{E}^{(2)}$ value for $\mathrm{A}-\mathrm{a}, \mathrm{A}-\mathrm{d}, \mathrm{B}-\mathrm{a}, \mathrm{B}-\mathrm{d}, \mathrm{C}-\mathrm{a}$ and $\mathrm{C}-\mathrm{d}$ adsorption models around adsorption site are listed in Table S4 in supplementary data. According to calculated results, the strongest intermolecular interaction between donor orbital and acceptor orbital of A-a and A-d models is observed in $v \mathrm{~N}_{3}-\mathrm{B}_{4} \rightarrow v^{*} \mathrm{~N}_{2}-\mathrm{B}_{3}$ and $v \mathrm{~N}_{2}-\mathrm{B}_{1} \rightarrow v^{*} \mathrm{~N}_{3}-\mathrm{B}_{2}$ with $\mathrm{E}^{(2)}$ $=8.74$ and $9.47 \mathrm{Kcal} / \mathrm{mol}$ respectively, for the B-a and B-d models the strongest intermolecular interaction occur in $v \mathrm{~N}_{3}-\mathrm{B}_{3} \rightarrow v^{*} \mathrm{~N}_{6}-\mathrm{B}_{7}$ and $v \mathrm{~N}_{4}-\mathrm{Ni} \rightarrow v^{*} \mathrm{~N}_{1}-\mathrm{B}_{4}$ with $\mathrm{E}^{(2)}=9.44$ and $10.24 \mathrm{Kcal} / \mathrm{mol}$ respectively. For the $\mathrm{C}$-a and $\mathrm{C}$-d models the strongest intermolecular interaction occur in $v \mathrm{~N}_{3}$ -

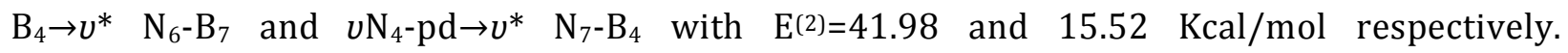
Comparison results indicate that the increase order of $\mathrm{E}^{(2)}$ for adsorption of MCP on the surface of pristine, $\mathrm{Ni}$ and Pd functionalized B12N12 is in order: C-d>B-d>A-d; C-a> B-a> A-a. This result demonstrates that with functionalizing $\mathrm{Pd}$ and $\mathrm{Ni}$ atoms the value of the stabilization energy $\mathrm{E}^{(2)}$ of system increases significantly from pristine models and so the most charge transfer occurs between donor to acceptor orbitals of Ni \& Pd functionalized models. The bonding stability between MCP and $\mathrm{Ni} \& \mathrm{Pd}$ functionalized B12N12 nanocage is more than pristine model.

\section{Conclusions}

In this work, a computational method was applied to investigate the adsorption and interaction of Mercaptopyridine on the surface of pristine, Ni, and Pd functionalized B12N12 nanocage. The thermodynamic parameters of all adsorption models were exothermic and favorable in energetically viewpoint. The calculated Gibbs free energies in gas, water and ethanol phases were in order: $\Delta \mathrm{G}_{\text {gas }}(-33.50 \mathrm{kcal} / \mathrm{mol})>\Delta \mathrm{G}_{\text {Ethanol }}(-22.84 \mathrm{kcal} / \mathrm{mol})>\Delta \mathrm{G}_{\text {water }}(-21.05 \mathrm{kcal} / \mathrm{mol})$. It was found that, the adsorption process in the gas phase was more favorable than water or 
ethanol phases. The positive values of $\Delta \mathrm{N}, \Delta \rho_{\mathrm{NB}}$ and $\Delta \rho_{\text {Mullikan }}$ indicated that the charge transfer occurred from MCP molecule toward to nanocluster surface. The RDG results confirmed that the most interaction between the MCP and B12N12 nanocage was van der Walls type. The NBO results demonstrated that the functionalizing Pd atom increased the value of the stabilization energy $E^{(2)}$ and charge transfer between the donor and acceptor orbital. To sum up, the calculated results demonstrated that the $\mathrm{Ni}$ functionalized B12N12 nanocage was a good candidate to prepare the adsorbent for the MCP molecule in the gas phase and the pristine B12N12 nanocluster (A-a model) with lower recovery time that was suitable for making sensor for the MCP molecule.

\section{Acknowledgments}

The author would like to appreciate the Computational Information Center of Malayer University for providing the necessary facilities to carry out this research.

\section{Supplementary Data}

Tables S1-S6 and Figures S1-S5 are presented in supplementary data.

\section{References}

[1] Millo D., Ranieri A., Koot W., Gooijer C., Van der Zwan G. Anal. Chem., 2006, 78:5622

[2] Ozoemena K.I., Nyokong T. Electrochem. Acta., 2006, 51:2669

[3] Jensen R.A., Sherin J., Emory S.R. Appl. Spectrosc., 2007, 61:832

[4] Wright S.W., Hallstrom K.N. J. Org. Chem., 2006, 71:1080

[5] Taniguchi I., Yoshimoto S., Yoshida M., Kobayashi S., Miyawaki T., Aono Y., Sunatsuki Y., Taira H. Electrochim. Acta, 45:2843

[6] Gui J.Y., Lu F., Stern D.A., Hubbard A.T. J. Electroanal. Chem. Interfacial Electrochem., 1990, 292:245

[7] Shokuhi Rad A. J. Alloys Compound., 2016, 682:345

[8] Zhu Y.C., Bando Y., Yin L.W., Golberg D. Chem. Eur. J., 2004, 10:3667

[9] Ganji M.D., Yazdani H., Mirnejad A. Phys. E., 2010, 42:2184

[10] Beheshtian J., Peyghan A.A., Bagheri Z., Kamfiroozi M. Struct. Chem., 2012, 23:1567

[11] Baei M.T., Bagheri Z., Peyghan A.A. Struct. Chem., 2013, 24:1039

[12] Beheshtian J., Peyghan A.A., Bagheri Z. J. Mol. Model., 2013, 19:833

[13] Castro M., Anota E. C., Struct. Chem., 2019, 30:195

[14] Carreto Escobar J., Salazar Villanueva M., Bautista Hernández A., Cortés-Arriagada D., Chigo Anota E. J. Mole. Graph. Mod., 2019, 86:27 
[15] Oku T., Nishiwaki A., Narita I. Sci. Tech. Adv. Mater., 2004, 5:635

[16] Beheshtian J., Bagheri Z., Kamfiroozi M., Ahmadi A. J. Mol. Model., 2012, 18:2653

[17] Iijima S., Brabec C., Maiti A., Bernholc J. J. Chem. Phys., 1996, 104:2089

[18] Oku T., Kuno M., Kitahara H., Narita I. Int. J. Inorg. Mater., 2001, 3:597

[19] Seifert G., Fowler R., Mitchell D., Porezag D., Frauenheim T. Chem. Phys. Lett., 1997, 268:352

[20] Bahrami A., Seidi S., Baheri T., Aghamohammadi M. Superlatt. Microstruct., 2013, 64:265

[21] Esrafili M.D., Nurazar R. Superlatt. Microstruct., 2014, 67:54

[22] Shakerzadeh E. Physica. E. 2016, 78:1

[23] Shokuhi Rad A. Semiconductors, 2017, 51:134

[24] Peyghan A.A., Soleymanabadi H. Curr. Sci., 2015, 108:1910

[25] Beheshtian J., Bagheri Z., Kamfiroozi M., Ahmadi A. Microelectron. J., 2011, 42:1400

[26] Vessally E., Soleimani-Amiri S., Hosseinian A., Edjlali L., Bekhradni A. Physica E., 2017, 87:308

[27] Quiñonero D., Frontera A., Deyà P.M. J. Phys. Chem. C, 2012, 116:21083

[28] Baei M.T. Heteroat. Chem., 2013, 24:476

[29] Shokuhi Rad A., Ayub K. Int. J. hydrogen. energy., 2016, 41:22182

[30] Beheshtian J., Peyghan A.A., Bagheri Z., Kamfiroozi M. Struct. Chem., 2012, 23:1567

[31] Shokuhi Rad A., Ayub K. Vacuum, 2016, 131:135

[32] Shakerzadeh E., Khodayar E., Noorizadeh S. Computat. Mater. Sci., 2016, 118:155

[33] Bezi Javan M., Soltani A., Lemeski E.T., Ahmadi A., Moazen Rad S. Superlatt. Microstruct., 2016, 100:24

[34] Esrafili M.D., Nurazar R. Surface Sci., 2014, 626:44

[35] Bahrami A., Balooch Qarai M., Hadipour N.L. Comput. Theo. Chem., 2017, 1108:63

[36] Shokuhi Rad A., Ayub K. Solid State Sci., 2017, 69:22

[37] Rezaei-Sameti M., Javadi Jukar N. J. Nanostruct. Chem., 2017, 7:293

[38] Rezaei-Sameti M., Moradi F. J. Inc. Phenom. Macrocycl. Chem., 2017, 88:209

[39] Rezaei-Sameti M., Bagheri M. J. Phys. Theo. Chem., 2017, 14:63

[40] Rezaei-Sameti M., Behbahani H.J. Phys. Chem. Res., 2018, 6:31

[41] Rezaei-Sameti M., Zanganeh F. J. Sulfur Chem., 2017, 38:384

[42] Frisch M.J., Trucks G.W., Schlegel H.B., Scuseria G.E., Robb M.A., Cheeseman J.R., Scalmani G., Barone V., Mennucci B., Petersson G.A., Nakatsuji H., 2009. Gaussian 09, Gaussian, Inc. Wallingford, CT, 32, 5648 [43] Yanai T., Tew D.P., Handy N.C. Chem. Phys. Lett., 2004, 393:51

[44] Scalmani G., Frisch M.J. J. Chem. Phys., 2010, 132:114110

[45] Parr R.G., Donnelly R.A., Levy M., Palke W.E. J. Chem. Phys., 1978, 68:3801 
[46] Parr R.G., Yang W. J. Am. Chem. Soc., 1987, 106:4049

[47] Gorbunova M., Shein I., Makurin Y.N., Ivanovskaya V., Kijko V., Ivanovskii A. Physica E., 2008, 41:164

[48] He J., Wu K., Sa R., Li Q., Wei Y. Appl. phys. lett., 2010, 97:051901

[49] Arivazhagan M., Manivel S., Jeyavijayan S., Meenakshi R. Spectrochim. Acta A Mol. Biomol. Spectroscopy, 2015, 134:493

[50] Reed A.E., Curtiss L.A., Weinhold F. Chem. Rev., 1988, 88:899

[51] Johnson E.R., Keinan S., Mori-Sanchez P., Contreras-Garcia J., Cohen A.J., Yang W. J. Am. Chem. Soc., 2010, 132:6498

[52] Ziołkowski M., Grabowski S.J., Leszczynski J. J. Phys. Chem. A, 2006, 110:6514

[53] Beheshtian J., Bagheri Z., Kamfiroozi M., Ahmadi A. Microelectron. J., 2011, 42:1400

[54] Yourdkhani S., Korona T., Hadipour N.L. J. Phys. Chem. A., 2015, 119:6446

[55] Vessally E., Esrafili M.D., Nurazar R., Nematollahi P., Bekhradni A. Struct. Chem., 2017, $28: 735$

[56] Schedin F., Geim A., Morozov S., Hill E., Blake P., Katsnelson M., Novoselov K. Nature Mater., 2007, 6:652

[57] Vessally E., Behmagham F., Massuomi B., Hosseinian A., Nejati K. J. Mol. Model., 2017, 23:138

[58] Bader R.F.W. Atoms in Molecules: A Quantum Theory, Oxford University Press, Oxford, U.K., 1990

[59] Keith T.A., AIMAll, version 14.04.17; TK Gristmill Software: Overland Park, KS, 2014

[60] Lu T., Chen F. J. Computat. Chem., 2012, 33:580

[61] Cossi M., Barone V. J. Chem. Phys., 2001, 115:4708

[62] Sun Y.T., Huang P.Y., Lin C.H., Lee K.R., Lee M.T. Biophys. J., 2016, 110:414

[63] de Assis J.L., Grobas I.L., Signoretti P.V.P., Fernandes A.M., Miranda M.A.C., Silva B.F.B., Valverde R., Einicker-Lamas M. Biophys. J., 2016, 110:489a

[64] Nataraj A., Balachandran V., Karthick T. J. Mol. Struct., 2012, 1022:94

How to cite this manuscript: M. Rezaei-Sameti*, M. Jafari, Effect of Ni and Pd Transition Metal Functionalized on Interaction of Mercaptopyridine with B12N12 Nanocage: NBO, AIM, DFT, TD-DFT Study. Chemical Methodologies 4(4), 2020, 494-513. DOI:10.33945/SAMI/CHEMM.2020.4.10. 